\section{TATRA \\ MOUNTaiNS \\ Mathematical Publications}

DOI: $10.2478 / \mathrm{tmmp}-2021-0025$

Tatra Mt. Math. Publ. 79 (2021), 149-162

\title{
EXISTENCE OF THE ASYMPTOTICALLY PERIODIC SOLUTION TO THE SYSTEM OF NONLINEAR NEUTRAL DIFFERENCE EQUATIONS
}

\author{
Ewa Schmeidel-Mągorzata Zdanowicz \\ Institute of Computer Science, University of Bialystok, Białystok, POLAND
}

ABSTRACT. The system of nonlinear neutral difference equations with delays in the form

$$
\left\{\begin{array}{l}
\Delta\left(y_{i}(n)+p_{i}(n) y_{i}\left(n-\tau_{i}\right)\right)=a_{i}(n) f_{i}\left(y_{i+1}(n)\right)+g_{i}(n), \\
\Delta\left(y_{m}(n)+p_{m}(n) y_{m}\left(n-\tau_{m}\right)\right)=a_{m}(n) f_{m}\left(y_{1}(n)\right)+g_{m}(n),
\end{array}\right.
$$

for $i=1, \ldots, m-1, m \geq 2$, is studied. The sufficient conditions for the existence of an asymptotically periodic solution of the above system, are established. Here sequences $\left(p_{i}(n)\right), i=1, \ldots, m$, are bounded away from -1 . The presented results are illustrated by theoretical and numerical examples.

\section{Introduction}

The aim of this paper is to prove the existence theorem for a nonlinear difference system of $m(m \geq 2)$ equations given below

$$
\left\{\begin{array}{l}
\Delta\left(y_{i}(n)+p_{i}(n) y_{i}\left(n-\tau_{i}\right)\right)=a_{i}(n) f_{i}\left(y_{i+1}(n)\right)+g_{i}(n), \\
\Delta\left(y_{m}(n)+p_{m}(n) y_{m}\left(n-\tau_{m}\right)\right)=a_{m}(n) f_{m}\left(y_{1}(n)\right)+g_{m}(n),
\end{array}\right.
$$

where $i \in\{1, \ldots, m-1\}$ and $\Delta$ stands for the forward difference operator, i.e., $\Delta u(n)=u(n+1)-u(n)$. Let $\mathbb{N}=\{0,1,2, \ldots\}$ and $\tau_{i} \in \mathbb{N}$, where $i=1, \ldots, m$. Set $n_{0}=\max \left\{\tau_{1}, \ldots, \tau_{m}\right\}$ and $\mathbb{N}_{n_{0}}=\left\{n_{0}, n_{0}+1, \ldots\right\}$. We consider system (11) for $n \in \mathbb{N}_{n_{0}}$. Moreover, $a_{i}, g_{i}, p_{i}: \mathbb{N}_{n_{0}} \rightarrow \mathbb{R}, i \in\{1, \ldots, m\}$ are given real

(C) 2021 Mathematical Institute, Slovak Academy of Sciences.

2010 Mathematics Subject Classification: 39A10, 39A23.

Keywords: Difference equation, delays, neutral type, periodicity, asymptotic behaviour.

(c) (1) $\Theta$ Licensed under the Creative Commons BY-NC-ND 4.0 International Public License. 
sequences, $y_{i}: \mathbb{N} \rightarrow \mathbb{R}, i=1, \ldots, m$, are unknown real sequences and functions $f_{i}: \mathbb{R} \rightarrow \mathbb{R}$. Throughout this paper, $Y=\left(y_{1}, \ldots, y_{m}\right)$ and $Y(n)$ denotes $\left(y_{1}(n), \ldots, y_{m}(n)\right) \in \mathbb{R}^{m}$.

The term 'neutral' was introduced by Kamenskii in the mid-20th century in the continuous case (see [13]). In 1955, the classification of equations as retarded, neutral, or advanced was used by Myshkis [18. An equation of neutral type represents a system in which the present rate of change of a quantity depends on the past rate of change as well as the past and present values of the quantity. Experience in mathematical modelling has shown that the evolution equation of actual processes retardation are often neutral type equations. Besides its theoretical interest, strong interest in the study of the asymptotic and periodic behaviour of solutions of neutral type equations is motivated by the fact that they arise in many areas of applied mathematics, such as population dynamics, transport problems, and dynamical behaviour of delayed network systems. So, neutral equations have long played an important role in the history of theoretical population dynamics and there is no doubt that they will continue to serve as indispensable tools in future investigations.

Asymptotic properties of nonlinear neutral difference equations have been widely studied in many papers, for instance in article by Jankowski and Schmeidel [11, 12, Migda et al. [15, 16, Wang and Sun [26]. Wang and Young 25] investigated the existence of positive periodic solutions to one equation

$$
\Delta(y(n)-c y(n-m))=a(n) y(n)+f(n ; y(n-m)),
$$

where $a(n)=a(n+\omega), f(n+\omega ; u)=f(n ; u), c$ is the positive constant and $\omega, m$ are positive integers. Philos and Purnaras 21 examined the asymptotic behaviour, the nonoscillation and the stability of the solutions of the equation in the form

$$
\Delta\left(y_{n}+\sum_{i \in I} c_{i} y_{n-\sigma_{i}}\right)=a(n) y_{n}+\sum_{i \in J} b_{j}(n) y_{n-\tau_{j}}
$$

for $c_{i}$ - real numbers and $a, b_{j}$ - real periodic sequences. Positive periodic solutions were the aim of the study of Nalini and Banu [19. They considered the system

$$
\begin{aligned}
u_{i}(t+1)= & a_{i}(t) u_{i}(t)+\sum_{j=1}^{\infty} b_{i j}(t) f_{j}\left(u_{j}(t)\right)+\sum_{j=1}^{\infty} c_{i j}(t) \Delta\left(u_{j}(t-\tau)\right) \\
& +\sum_{j=1}^{\infty} d_{i j}(t) f_{j}\left[\sum_{\eta_{1}}^{\infty} h_{j}(\eta) u_{j}(t-\eta)\right]+I_{i}(t), \quad i \in\{1, \ldots, m\} .
\end{aligned}
$$




\section{EXISTENCE OF THE ASYMPTOTICALLY PERIODIC SOLUTION}

Ren and Siegmund 22 investigated the difference equation with variable delay

$$
y_{n+1}-c y_{n+1-\tau(n+1)}=a_{n} y_{n}+\lambda h_{n} f\left(y_{n-\tau(n)}\right),
$$

where $n \in \mathbb{Z}, a_{n}, h_{n}$ are $\omega$-periodic positive sequences, $\tau(n)$ is an $\omega$-periodic integer sequence, $f \in C([0 ;+\infty) ;[0 ;+\infty)), \lambda>0$ and $0<c<1$. Boundedness and existence of nonoscillatory solutions of some classes of neutral difference equations were also studied by Thandapani, Karunakaran and Arockiasamy in [24] and by Zhou et al. [27, 28. Oscillation of solutions of nonlinear neutral difference equations was investigated, for example, in papers by Agarwal et al. [2, 3], Bolat and Akin [5], and Parhi and Tripathy [20]. In [17], the authors established the sufficient conditions in order to get the existence theorem of a bounded solution of (11). Here, conditions for the existence of asymptotically periodic solution are presented.

Asymptotically periodic solutions were investigated among others for Volterra difference equations in [1,6 10, as well as in 4, 14, for the rational difference equations.

Since any periodic sequence is bounded, then the conditions ensuring existence of a periodic solution of (1) are sufficient for existence of bounded solution to system (11). Therefore, results presented here are complementary to the results obtained in [17].

Let us recall some basic facts.

Definition 1. Let $\tau$ be a positive integer. The sequence $y: \mathbb{N} \rightarrow \mathbb{R}$ is called $\tau$-periodic, if $y(n+\tau)=y(n)$ for all $n \in \mathbb{N}$. The sequence $y$ is called asymptotically $\tau$-periodic, if there exist two sequences $u, v: \mathbb{N} \rightarrow \mathbb{R}$ such that $u$ is $\tau$-periodic, $\lim _{n \rightarrow \infty} v(n)=0$ and $y(n)=u(n)+v(n)$ for all $n \in \mathbb{N}$.

As a solution of system (10) we treat a vector $Y$ such that its components $y_{1}, \ldots, y_{m}$ satisfy system (11) for sufficiently large $n$. Let $\tau=\left(\tau_{1}, \ldots, \tau_{m}\right)$. Sequence $Y$ that satisfies (11) is called $\tau$-periodic if

$$
\left(y_{1}(n), \ldots, y_{m}(n)\right)=\left(y_{1}\left(n+\tau_{1}\right), \ldots, y_{m}\left(n+\tau_{m}\right)\right) .
$$

It means that the solution $Y$ of (11) is periodic, if all its components are periodic. Solution $Y$ of (11) is asymptotically periodic, if all its components are asymptotically periodic.

By $(\mathcal{B},\|\cdot\|)$ we denote the Banach space of all bounded sequences in $\mathbb{R}^{m}$ with the supremum norm, i.e.

where

$$
\mathcal{B}:=\left\{Y: \mathbb{N} \rightarrow \mathbb{R}^{m}:\|Y\|=\sup _{n \in \mathbb{N}}|Y(n)|<\infty\right\},
$$

$$
|Y|=\max _{i \in\{1,2, \ldots, m\}}\left|y_{i}\right|
$$


Let $r$ be the fixed positive real number. Define a set

$$
S:=\{Y \in \mathcal{B}:\|Y\| \leq r \text { and } Y \text { is asymptotically } \tau \text {-periodic }\} .
$$

Theorems given below will be used in the next paragraphs.

Theorem 1 (Tychonoff's Theorem, 23]). The product of any non-empty class of compact spaces is compact.

LEMMA 1. $S$ is convex and compact subset of $\mathcal{B}$.

P r o o f. It is easy to see that $S$ is convex subset of $\mathcal{B}$. Indeed, let $Y, Z \in S$ and $\alpha \in[0,1]$. If

$$
-r \leq y_{i}(n), z_{i}(n) \leq r
$$

for $i=1, \ldots, m, n \in \mathbb{N}$, then

$$
\begin{gathered}
-r \alpha \leq \alpha y_{i}(n) \leq r \alpha, \\
-r(1-\alpha) \leq(1-\alpha) z_{i}(n) \leq r(1-\alpha),
\end{gathered}
$$

and

$$
-r \leq \alpha y_{i}(n)+(1-\alpha) z_{i}(n) \leq r \quad \text { for } i=1, \ldots, m, n \in \mathbb{N}
$$

which means that $S$ is convex.

Now, we prove that $S$ is also compact. By virtue of Tychonoff's Theorem 1 . in order to prove that $S$ is compact, it is enough to prove that the set (for $i=$ $1, \ldots, m)$

$$
B_{i}:=\left\{y_{i}: \mathbb{N} \rightarrow \mathbb{R}: \sup _{n \in \mathbb{N}}\left|y_{i}(n)\right| \leq r \text { and } y_{i} \text { is asymptotically } \tau_{i} \text {-periodic }\right\},
$$

is compact. Since $y_{i}$ is asymptotically $\tau_{i}$-periodic for $i=1, \ldots, m$, there exist sequences $u_{i}, v_{i}: \mathbb{N} \rightarrow \mathbb{R}$ such that $y_{i}(n)=u_{i}(n)+v_{i}(n)$ for all $n \in \mathbb{N}$ and $u_{i}\left(n+\tau_{i}\right)=u_{i}(n), n \in \mathbb{N}$ and $\lim _{n \rightarrow \infty} v_{i}(n)=0$. Hence, the terms of the sequence $\left(u_{i}\right)$ are as follows $\left\{C_{i 1}, C_{i 2}, \ldots, C_{i \tau_{i}}, C_{i 1}, C_{i 2}, \ldots\right\}$, where $C_{i j} \in \mathbb{R}$, $i=1, \ldots, m, j=1, \ldots, \tau_{i}$.

Let us take $\varepsilon_{i}>0$. There exists $n^{*} \in \mathbb{N}$ such that $\left|y_{i}(n)-C_{i j}\right|<\varepsilon_{i}$ for some $j=1, \ldots, \tau_{i}$ and $n>n^{*}$. Denote $\rho_{i}:=\left\lfloor\frac{r}{\varepsilon_{i}}\right\rfloor+1$, where $\lfloor\cdot\rfloor$ is the floor function.

Then the $\varepsilon_{i}$-neighbourhood of the points

$$
\left(\delta_{i 1}, \delta_{i 2}, \ldots, \delta_{i n^{*}}, C_{i(j+1)}, \ldots, C_{i \tau_{i}}, C_{i 1}, C_{i 2}, \ldots, C_{i \tau_{i}}, \ldots\right)
$$

where $\delta_{i j} \in\left\{0, \pm \varepsilon_{i}, \pm 2 \varepsilon_{i}, \ldots, \pm \rho_{i} \varepsilon_{i}\right\}, j=1, \ldots, n^{*}$, is the $\varepsilon_{i}$-cover of the set $B_{i}$. Cardinality of this $\varepsilon_{i}$-cover is finite and equal to $\left(2 \rho_{i}+1\right)^{n^{*}}$. Hence, the set $B_{i}$ is compact. 


\section{EXISTENCE OF THE ASYMPTOTICALLY PERIODIC SOLUTION}

\section{Major outputs}

We can now formulate theorem, which gives the sufficient condition for the existence an asymptotically periodic sequence satisfying (1).

TheOREM 2. Let $i=1, \ldots, m$. If

$$
\sum_{s=n_{0}}^{\infty}\left|a_{i}(s)\right|<\infty
$$

$\left(g_{i}(n)\right)$ are $\tau_{i}$-periodic sequences such that $\sum_{s=0}^{\tau_{i}-1} g_{i}(s)=0$,

$p_{i}(n) \neq-1$ for each $n \in \mathbb{N}$, and $\left(p_{i}(n)\right)$ are $\tau_{i}$-periodic sequences,

$$
f_{i}: \mathbb{R} \rightarrow \mathbb{R} \text { are continuous functions, }
$$

then system (1) has an asymptotically $\tau$-periodic solution.

P r o o f. The series $\sum_{s=0}^{\infty} g_{i}(s), i=1 \ldots, m$, by assumption (3), are - in general - divergent but each subtotal is always bounded. Hence, there exists the positive constant

$$
c_{g}:=\max _{\substack{n \in\left\{0, \ldots, \tau_{i}-1\right\} \\ i=1, \ldots, m}}\left|\sum_{s=0}^{n} g_{i}(s)\right| \text {. }
$$

Condition (41) implies existence of the positive constant

$$
c_{p}:=\sup _{\substack{n \in \mathbb{N} \\ i=1, \ldots m}} \frac{1}{\left|1+p_{i}(n)\right|} .
$$

From now on we make the assumption that

$$
r \geq 3 c_{p} c_{g}
$$

Since condition (5) is satisfied, we have

$$
M:=\max _{i=1, \ldots, m}\left\{\left|f_{i}(t)\right| \text { for }|t| \leq r\right\} .
$$

Let us take $n_{1} \geq n_{0}$ such that

$$
\sum_{s=n_{1}}^{\infty}\left|a_{i}(s)\right|<\frac{r}{3 M c_{p}} \quad \text { for } \quad i=1, \ldots, m
$$

For $y_{i} \in S, i=1 \ldots, m$, we have

$$
\begin{aligned}
y_{i}\left(n-\tau_{i}\right) & =u_{i}\left(n-\tau_{i}\right)+v_{i}\left(n-\tau_{i}\right) \\
& =u_{i}(n)+v_{i}\left(n-\tau_{i}\right)=y_{i}(n)-v_{i}(n)+v_{i}\left(n-\tau_{i}\right) .
\end{aligned}
$$

Moreover, since $\lim _{n \rightarrow \infty}\left(v_{i}\left(n-\tau_{i}\right)-v_{i}(n)\right)=0$ and $p_{i}$ is periodic for $i=1, \ldots, m$, we can write

$$
\left|\frac{p_{i}(n)}{1+p_{i}(n)}\right|\left|v_{i}\left(n-\tau_{i}\right)-v_{i}(n)\right| \leq \frac{r}{3}, \quad n \geq n_{2},
$$

for some $n_{2} \geq n_{0}$. 
Let $n_{3}=\max \left\{n_{1}, n_{2}\right\}$. We define the mapping $T: S \rightarrow \mathcal{B}, T=\left(T_{1}, \ldots, T_{m}\right)$ in such a way

$$
\left(T_{i} Y\right)(n)= \begin{cases}\left(T_{i} Y\right)\left(n_{3}\right), & 0 \leq n<n_{3}, \\ \frac{1}{1+p_{i}(n)}\left(-\sum_{s=n}^{\infty} a_{i}(s) f_{i}\left(y_{i+1}(s)\right)\right. & \\ \left.+\sum_{s=n_{3}}^{n-1} g_{i}(s)-p_{i}(n)\left(v_{i}\left(n-\tau_{i}\right)-v_{i}(n)\right)\right), & n \geq n_{3},\end{cases}
$$

where $i \in\{1, \ldots, m-1\}$ and

$$
\left(T_{m} Y\right)(n)= \begin{cases}\left(T_{m} Y\right)\left(n_{3}\right), & 0 \leq n<n_{3}, \\ \frac{1}{1+p_{m}(n)}\left(-\sum_{s=n}^{\infty} a_{m}(s) f_{m}\left(y_{1}(s)\right)\right. & \\ \left.+\sum_{s=n_{3}}^{n-1} g_{m}(s)-p_{m}(n)\left(v_{m}\left(n-\tau_{m}\right)-v_{m}(n)\right)\right), & n \geq n_{3},\end{cases}
$$

where $v_{i}$ is part of $y_{i}$ such that $\lim _{n \rightarrow \infty} v_{i}(n)=0$.

We will show that $T$ satisfies the assumptions of Schauder's Fixed Point Theorem. We claim that, if $Y \in S$, then $T Y \in S$. For $n \geq n_{3}, i \neq m$, we have

$$
\begin{aligned}
\left|\left(T_{i} Y\right)(n)\right|= & \mid \frac{1}{1+p_{i}(n)}\left(-\sum_{s=n}^{\infty} a_{i}(s) f_{i}\left(y_{i+1}(s)\right)\right. \\
& \left.+\sum_{s=n_{3}}^{n-1} g_{i}(s)-p_{i}(n)\left(v_{i}\left(n-\tau_{i}\right)-v_{i}(n)\right)\right) \mid \\
\leq & \frac{1}{\left|1+p_{i}(n)\right|} \sum_{s=n}^{\infty}\left|a_{i}(s)\right|\left|f_{i}\left(y_{i+1}(s)\right)\right| \\
& +\frac{1}{\left|1+p_{i}(n)\right|}\left|\sum_{s=n_{3}}^{n-1} g_{i}(s)\right|+\left|\frac{p_{i}(n)}{1+p_{i}(n)}\right| v_{i}\left(n-\tau_{i}\right)-v_{i}(n) \mid \\
\leq & c_{p} \frac{r}{3 M c_{p}} M+c_{p} c_{g}+\frac{r}{3} \leq \frac{r}{3}+\frac{r}{3}+\frac{r}{3}=r
\end{aligned}
$$

since (31), (6), (7) and (9). Estimations for $i=m$ hold analogously. Moreover, let us notice that $\frac{1}{1+p_{i}(n)} \sum_{s=n_{3}}^{n-1} g_{i}(s)$ is $\tau_{i}$-periodic, whereas

$$
\frac{p_{i}(n)}{1+p_{i}(n)}\left(v_{i}\left(n-\tau_{i}\right)-v_{i}(n)\right) \text { and } \frac{1}{1+p_{i}(n)} \sum_{s=n}^{\infty} a_{i}(s) f_{i}\left(y_{i+1}(s)\right)
$$

tend to 0 , if $n \rightarrow \infty$.

In order to prove continuity of $T$, we set $Y_{j}=\left(y_{j, 1}, \ldots, y_{j, m}\right) \in S$ for $j \in \mathbb{N}$ and $i \in\{1, \ldots, m\}$ there is $y_{j, i}(n) \rightarrow y_{i}(n)$ when $j \rightarrow \infty$. The set $S$ is closed. 
Therefore, $Y=\left(y_{1}, \ldots, y_{m}\right) \in S$. By (3) and (5) we receive

$$
\begin{aligned}
\mid & \left(T_{i} Y_{j}\right)(n)-\left(T_{i} Y\right)(n) \mid \\
\leq & \frac{1}{\left|p_{i}(n)+1\right|} \sum_{s=n}^{\infty}\left|a_{i}(s)\right|\left|f_{i}\left(y_{j, i+1}(s)\right)-f_{i}\left(y_{i+1}(s)\right)\right| \\
& +\left|\frac{p_{i}(n)}{p_{i}(n)+1}\right|\left|v_{j, i}\left(n-\tau_{i}\right)-v_{i}\left(n-\tau_{i}\right)\right|+\left|\frac{p_{i}(n)}{p_{i}(n)+1}\right|\left|v_{j, i}(n)-v_{i}(n)\right| \\
\leq & \sup _{s \geq n}\left|f_{i}\left(y_{j, i+1}(s)\right)-f_{i}\left(y_{i+1}(s)\right)\right| \frac{1}{\left|p_{i}(n)+1\right|} \sum_{s=n}^{\infty}\left|a_{i}(s)\right| \\
& +\left|\frac{p_{i}(n)}{p_{i}(n)+1}\right|\left|v_{j, i}\left(n-\tau_{i}\right)-v_{i}\left(n-\tau_{i}\right)\right|+\left|\frac{p_{i}(n)}{p_{i}(n)+1}\right|\left|v_{j, i}(n)-v_{i}(n)\right| \\
\leq & c_{p} \cdot \frac{r}{3 M c_{p} s \geq n} \sup _{s}\left|f_{i}\left(y_{j, i+1}(s)\right)-f_{i}\left(y_{i+1}(s)\right)\right| \\
& +\left|\frac{p_{i}(n)}{p_{i}(n)+1}\right|\left|v_{j, i}\left(n-\tau_{i}\right)-v_{i}\left(n-\tau_{i}\right)\right| \\
& +\left|\frac{p_{i}(n)}{p_{i}(n)+1}\right|\left|v_{j, i}(n)-v_{i}(n)\right| \rightarrow 0 \quad \text { if } j \rightarrow \infty, \quad i=1, \ldots, m-1,
\end{aligned}
$$

since $f$ is continuous function and $(y(n))$ is an asymptotically $\tau$-periodic sequence. For $i=m$ the estimation is analogous, then omitted. Therefore,

$$
\left\|\left(T Y_{j}\right)-(T Y)\right\| \rightarrow 0 \quad \text { if } \quad j \rightarrow \infty
$$

and $T$ is the continuous mapping.

By Schauder's Fixed Point Theorem, there exists $Y$ such that $(T Y)(n)=Y(n)$. Final step is to verify if $Y$ satisfies system (1), where $n \geq n_{3}$. We have $(i=1, \ldots$ $\ldots, m-1)$

$$
\begin{aligned}
& y_{i}(n)=\frac{1}{1+p_{i}(n)}\left(-\sum_{s=n}^{\infty} a_{i}(s) f_{i}\left(y_{i+1}(s)\right)+\sum_{s=n_{3}}^{n-1} g_{i}(s)-p_{i}(n)\left(v_{i}\left(n-\tau_{i}\right)-v_{i}(n)\right)\right) \\
& \left(1+p_{i}(n)\right) y_{i}(n)=-\sum_{s=n}^{\infty} a_{i}(s) f_{i}\left(y_{i+1}(s)\right)+\sum_{s=n_{3}}^{n-1} g_{i}(s)-p_{i}(n)\left(v_{i}\left(n-\tau_{i}\right)-v_{i}(n)\right), \\
& y_{i}(n)+p_{i}(n)\left(y_{i}(n)+\left(v_{i}\left(n-\tau_{i}\right)-v_{i}(n)\right)\right)=-\sum_{s=n}^{\infty} a_{i}(s) f_{i}\left(y_{i+1}(s)\right)+\sum_{s=n_{3}}^{n-1} g_{i}(s) .
\end{aligned}
$$


Hence, because of (8), we obtain

$$
\begin{array}{r}
y_{i}(n)+p_{i}(n) y_{i}\left(n-\tau_{i}\right)=-\sum_{s=n}^{\infty} a_{i}(s) f_{i}\left(y_{i+1}(s)\right)+\sum_{s=n_{3}}^{n-1} g_{i}(s), \quad i=1, \ldots, m-1, \\
\Delta\left(y_{i}(n)+p_{i}(n) y_{i}\left(n-\tau_{i}\right)\right)=a_{i}(n) f_{i}\left(y_{i+1}(n)+g_{i}(n)\right), \quad i=1, \ldots, m-1 .
\end{array}
$$

The same method as above works if $i=m$. The proof is complete.

Note that for $p_{i}(n)=0, i \in\{1, \ldots, m\}, n \geq n_{3}$, system (11) is not of the neutral type, but Theorem 2 is still true.

Remark 1. Let us notice that all results obtained for system (11) are also true in case of one equality $\Delta(y(n)+p(n) y(n-\tau))=a(n) f(y(n))+g(n)$.

Example 1. Consider the example of system (1)

$$
\left\{\begin{array}{l}
\Delta\left(y_{1}(k)+p_{1}(k) y_{1}(k-3)\right)=a_{1}(k) y_{2}(k)+g_{1}(k), \\
\Delta\left(y_{2}(k)+p_{2}(k) y_{2}(k-2)\right)=a_{2}(k) y_{1}(k)+g_{2}(k) .
\end{array}\right.
$$

Here $\tau=\left(\tau_{1}, \tau_{2}\right)=(3,2), f_{1}(t)=t, f_{2}(t)=t$ and for $k \geq n_{0}=3$

$$
\begin{gathered}
p_{1}(k)=\left\{\begin{array}{c}
- \text { for } \quad k \equiv 0(\bmod 3), \\
1 \quad \text { for } k \equiv 1(\bmod 3), \\
5 \quad \text { for } k \equiv 2(\bmod 3),
\end{array}\right. \\
p_{2}(k)=\left\{\begin{array}{cl}
1 \quad \text { for } \quad k \equiv 0(\bmod 2), \\
7 \quad \text { for } \quad k \equiv 1(\bmod 2),
\end{array}\right. \\
a_{1}(k)=\left\{\begin{aligned}
& \frac{39}{2^{k+1}-2} \text { for } \quad k \equiv 0(\bmod 6), \\
& \frac{23}{2^{k+2}-2} \quad \text { for } \quad k \equiv 1(\bmod 6), \\
&-\frac{97}{2^{k+1}-2} \quad \text { for } \quad k \equiv 2(\bmod 6), \\
& \frac{39}{2^{k+2}-2} \quad \text { for } \quad k \equiv 3(\bmod 6), \\
& \frac{23}{2^{k+1}-2} \quad \text { for } \quad k \equiv 4(\bmod 6), \\
&-\frac{97}{2^{k+2}-2} \quad \text { for } \quad k \equiv 5(\bmod 6), \\
&-\frac{19}{2^{k+1}+2} \quad \text { for } \quad k \equiv 0(\bmod 6), \\
& \frac{53}{2^{k+2}+2} \quad \text { for } \quad k \equiv 1(\bmod 6), \\
&-\frac{19}{3 \cdot 2^{k+1}+2} \text { for } \quad k \equiv 2(\bmod 6), \\
& \frac{53}{2^{k+1}+2} \text { for } \quad k \equiv 3(\bmod 6), \\
&-\frac{19}{2^{k+2}+2} \text { for } \quad k \equiv 4(\bmod 6), \\
& \frac{53}{3 \cdot 2^{k+1}+2} \text { for } \quad k \equiv 5(\bmod 6),
\end{aligned}\right.
\end{gathered}
$$




$$
\begin{aligned}
& g_{1}(k)=\left\{\begin{array}{rll}
5 & \text { for } & k \equiv 0(\bmod 3), \\
14 & \text { for } & k \equiv 1(\bmod 3), \\
-19 & \text { for } & k \equiv 2(\bmod 3),
\end{array}\right. \\
& g_{2}(k)=\left\{\begin{array}{rll}
14 & \text { for } & k \equiv 0(\bmod 2), \\
-14 & \text { for } & k \equiv 1(\bmod 2) .
\end{array}\right.
\end{aligned}
$$

One of the solutions is

$$
\begin{aligned}
& y_{1}(k)=\left\{\begin{array}{lll}
1+\frac{1}{2^{k}} & \text { for } & k \equiv 0(\bmod 3), \\
2+\frac{1}{2^{k}} & \text { for } & k \equiv 1(\bmod 3), \\
3+\frac{1}{2^{k}} & \text { for } & k \equiv 2(\bmod 3),
\end{array}\right. \\
& y_{2}(k)=\left\{\begin{array}{lll}
1-\frac{1}{2^{k}} & \text { for } & k \equiv 0(\bmod 2), \\
2-\frac{1}{2^{k}} & \text { for } & k \equiv 1(\bmod 2) .
\end{array}\right.
\end{aligned}
$$

The following numerical example shows the system of the form (1) having both: periodic and nonperiodic solutions depending on chosen initial values.

EXAMPle 2. Consider the system

$$
\left\{\begin{array}{l}
\Delta\left(y_{1}(k)+\frac{(-1)^{k}}{10} y_{1}(k-1)\right)=\frac{1}{k^{2}}\left(y_{2}(k)\right)^{2}+(-1)^{k} \\
\Delta\left(y_{1}(k)+\frac{(-1)^{k}}{10} y_{1}(k-1)\right)=\frac{1}{k^{2}+1}\left(y_{1}(k)\right)^{2}+(-1)^{k}
\end{array}\right.
$$

All assumptions of Theorem 2 are satisfied and hence system (12) has an asymptotically 2-periodic solution. It is hard to find the solution of (12) in the analytical form since system (12) is nonlinear. Due to these problems we treat this example as the numerical illustration to Theorem 2. Figure 1 and Figure 2 show the trajectory of $y_{1}$ and $y_{2}$ received for initial conditions

$$
y_{1}(1)=y_{2}(1)=0, \quad y_{1}(2)=y_{2}(2)=-1 \text {. }
$$

Both plots suggest that solutions $y_{1}$ and $y_{2}$ are asymptotically 2-periodic. 
EWA SCHMEIDEL-MALGORZATA ZDANOWICZ

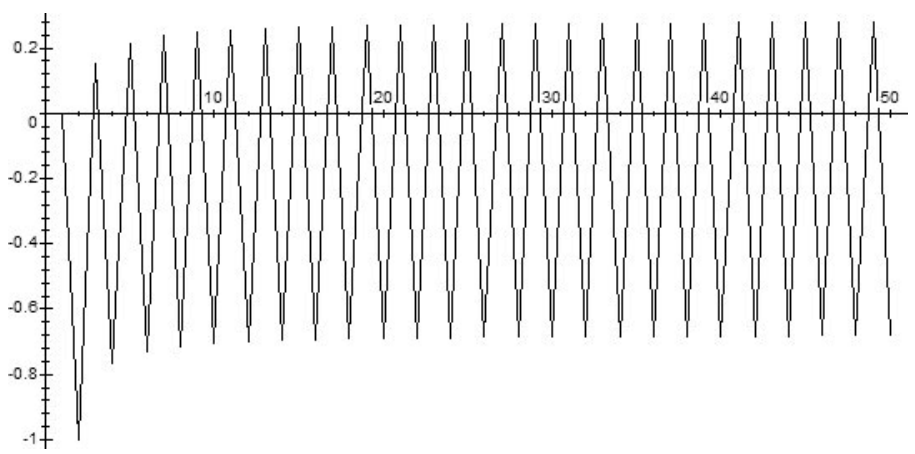

Figure 1. Trajectory of $y_{1}$.

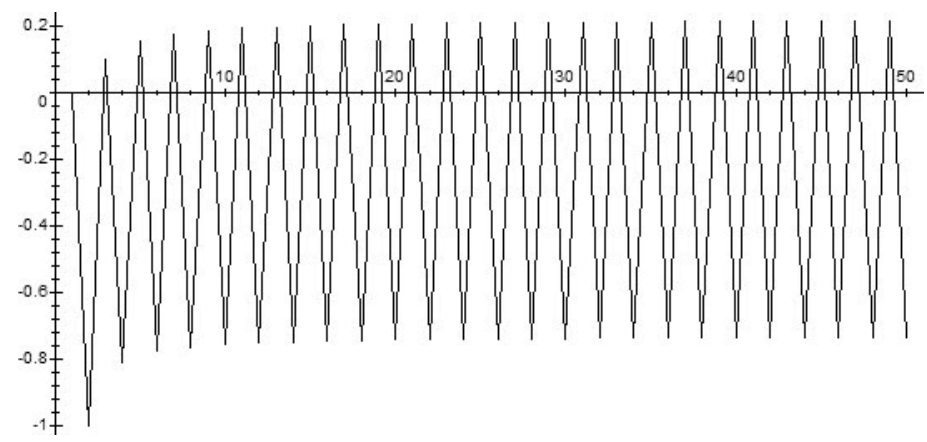

Figure 2. Trajectory of $y_{2}$.

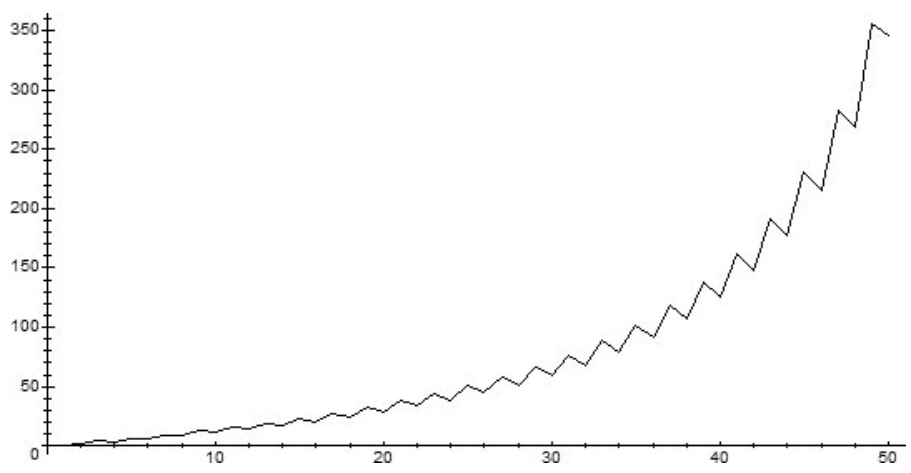

Figure 3. Trajectory of $y_{1}$. 


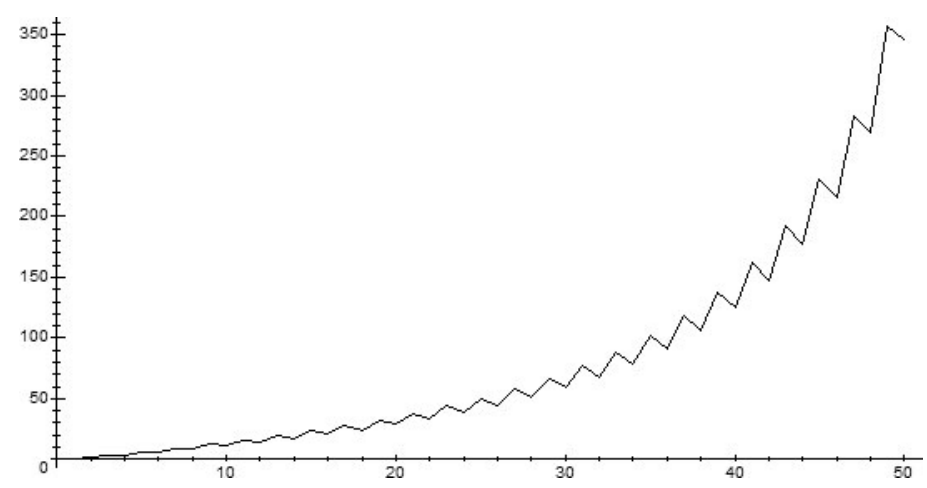

Figure 4. Trajectory of $y_{2}$.

System (12) has also solutions that are not asymptotically 2-periodic. In the following two figures (Fig.3 and Fig.4), there are trajectories of $y_{1}$ and $y_{2}$ for initial conditions

$$
y_{1}(1)=y_{2}(1)=1, \quad y_{1}(2)=y_{2}(2)=1.8 .
$$

The values of $y_{1}$ and $y_{2}$ tend to infinity as $k$ tends to infinity.

The following result may be proved in the same way as Theorem 2 :

Theorem 3. Let $i=1, \ldots, m$. If conditions (2), (3) and (5) hold,

$$
p_{i}(n) \neq-1 \text { for each } n \in \mathbb{N} \text {, and } \lim _{n \rightarrow \infty} p_{i}(n)=\beta \neq-1 \text {, }
$$

then system (11) has an asymptotically $\tau$-periodic solution.

The next examples refer to Theorem 3 ,

ExAmple 3. Consider the system below for $k>n_{0}=2$

$$
\left\{\begin{array}{l}
\Delta\left(y_{1}(k)+\left(1+\frac{1}{k^{2}}\right) y_{1}(k-2)\right)=\frac{2 k^{2}+2 k+1}{(1+k)^{2}\left(2 k^{2}+1\right)} y_{2}(k)+4 \cdot(-1)^{k+1}, \\
\Delta\left(y_{2}(k)+y_{2}(k-2)\right)=\left(\frac{1}{(k-2)^{2}}+\frac{1}{(k-1)^{2}}+\frac{1}{k^{2}}+\frac{1}{(k+1)^{2}}\right) y_{1}(k)+8 \cdot(-1)^{k} .
\end{array}\right.
$$

One of the solutions is $y_{1}(k)=(-1)^{k} \quad$ and $\quad y_{2}(k)=\left(2+\frac{1}{k^{2}}\right) \cdot(-1)^{k+1}$.

EXAMPLE 4. Let us consider the system

$$
\left\{\begin{array}{l}
\Delta\left(y_{1}(k)+p_{1}(k) y_{1}(k-2)\right)=a_{1}(k) y_{2}^{2}(k)+g_{1}(k), \\
\Delta\left(y_{2}(k)+p_{2}(k) y_{2}(k-3)\right)=a_{2}(k) y_{1}(k)+g_{2}(k) .
\end{array}\right.
$$

Here we have

$$
\tau=\left(\tau_{1}, \tau_{2}\right)=(2,3), \quad f_{1}(t)=t^{2}, \quad f_{2}(t)=t ;
$$

and for $k>n_{0}=3$,

$$
p_{1}(k)=4+\frac{1}{k^{4}}, \quad p_{2}(k)=\frac{1}{k^{4}},
$$


EWA SCHMEIDEL-MAtGORZATA ZDANOWICZ

$a_{1}(k)= \begin{cases}\frac{-5 k^{8}-16 k^{7}-19 k^{6}-21 k^{5}-4 k^{4}+2 k^{3}+k^{2}-2 k-1}{36 k^{10}+48 k^{9}-131 k^{8}-263 k^{7}-40 k^{6}+186 k^{5}+133 k^{4}+29 k^{3}+2 k^{2}}, & k \equiv 0(\bmod 6), \\ \frac{-5 k^{8}-16 k^{7}-21 k^{6}-19 k^{5}-2 k^{4}+8 k^{3}-7 k-3}{4 k^{10}+8 k^{9}-11 k^{8}-39 k^{7}-24 k^{6}+18 k^{5}+29 k^{4}+13 k^{3}+2 k^{2}}, & k \equiv 1(\bmod 6), \\ \frac{-5 k^{8}-16 k^{7}-19 k^{6}-21 k^{5}-4 k^{4}+2 k^{3}+k^{2}-2 k-1}{49 k^{10}+63 k^{9}-181 k^{8}-349 k^{7}-39 k^{6}+253 k^{5}+169 k^{4}+33 k^{3}+2 k^{2}}, & k \equiv 2(\bmod 6), \\ \frac{-5 k^{8}-16 k^{7}-21 k^{6}-19 k^{5}-2 k^{4}+8 k^{3}-7 k-3}{36 k^{10}+48 k^{9}-131 k^{8}-263 k^{7}-40 k^{6}+186 k^{5}+133 k^{4}+29 k^{3}+2 k^{2}}, & k \equiv 3(\bmod 6), \\ \frac{-5 k^{8}-16 k^{7}-19 k^{6}-21 k^{5}-4 k^{4}+2 k^{3}+k^{2}-2 k-1}{4 k^{10}+8 k^{9}-11 k^{8}-39 k^{7}-24 k^{6}+18 k^{5}+29 k^{4}+13 k^{3}+2 k^{2}}, & k \equiv 4(\bmod 6), \\ \frac{-5 k^{8}-16 k^{7}-21 k^{6}-19 k^{5}-2 k^{4}+8 k^{3}-7 k-3}{49 k^{10}+63 k^{9}-181 k^{8}-349 k^{7}-39 k^{6}+253 k^{5}+169 k^{4}+33 k^{3}+2 k^{2}}, & k \equiv 5(\bmod 6), \\ a_{2}(k)= \begin{cases}\frac{-k^{8}+2 k^{7}+2 k^{6}-8 k^{5}+42 k^{4}+8 k^{3}-94 k^{2}-107 k-34}{k^{10}-9 k^{8}-10 k^{7}+15 k^{6}+36 k^{5}+25 k^{4}+6 k^{3}}, \\ \frac{-k^{8}+2 k^{7}+11 k^{6}-37 k^{5}+40 k^{4}-26 k^{2}-31 k-10}{2 k^{10}-k^{9}-17 k^{8}-12 k^{7}+32 k^{6}+55 k^{5}+31 k^{4}+6 k^{3}}, \\ \frac{-k^{8}+2 k^{7}+5 k^{6}-27 k^{5}+74 k^{4}+10 k^{3}-111 k^{2}-126 k-40}{k^{10}-9 k^{8}-10 k^{7}+15 k^{6}+36 k^{5}+25 k^{4}+6 k^{3}}, & k \equiv 0(\bmod 6), \\ \frac{-k^{8}+2 k^{7}+2 k^{6}-8 k^{5}+42 k^{4}+8 k^{3}-94 k^{2}-107 k-34}{2 k^{10}-k^{9}-17 k^{8}-12 k^{7}+32 k^{6}+55 k^{5}+31 k^{4}+6 k^{3}}, & k \equiv 2(\bmod 6), \\ \frac{-k^{8}+2 k^{7}+11 k^{6}-37 k^{5}+40 k^{4}-26 k^{2}-31 k-10}{k^{10}-9 k^{8}-10 k^{7}+15 k^{6}+36 k^{5}+25 k^{4}+6 k^{3}}, & k \equiv 3(\bmod 6), \\ \frac{-k^{8}+2 k^{7}+5 k^{6}-27 k^{5}+74 k^{4}+10 k^{3}-111 k^{2}-126 k-40}{2 k^{10}-k^{9}-17 k^{8}-12 k^{7}+32 k^{6}+55 k^{5}+31 k^{4}+6 k^{3}}, & k \equiv 4(\bmod 6),\end{cases} \end{cases}$

$$
\begin{aligned}
& g_{1}(k)=\left\{\begin{aligned}
5, & k \equiv 0(\bmod 2), \\
-5, & k \equiv 1(\bmod 2),
\end{aligned}\right. \\
& g_{2}(k)=\left\{\begin{aligned}
-4, & k \equiv 0(\bmod 3), \\
5, & k \equiv 1(\bmod 3), \\
-1, & k \equiv 2(\bmod 3) .
\end{aligned}\right.
\end{aligned}
$$

One of the solutions is

$$
\begin{aligned}
& y_{1}(k)= \begin{cases}1+\frac{1}{k}, & k \equiv 0(\bmod 2), \\
2+\frac{1}{k}, & k \equiv 1(\bmod 2),\end{cases} \\
& y_{2}(k)= \begin{cases}6+\frac{1}{k}, & k \equiv 0(\bmod 3), \\
2+\frac{1}{k}, & k \equiv 1(\bmod 3), \\
7+\frac{1}{k}, & k \equiv 2(\bmod 3) .\end{cases}
\end{aligned}
$$




\title{
EXISTENCE OF THE ASYMPTOTICALLY PERIODIC SOLUTION
}

\author{
REFERENCES
}

[1] Adivar, M.- KOYUnCUOĞLU, H. C.-RAFFOUL, Y. N.: Periodic and asymptotically periodic solutions of systems of nonlinear difference equations with infinite delay, J. Difference Equ. Appl. 19 (2013), no. 12, 1927-1939, doi10.1080/10236198.2013.791688.

[2] AGARWAL, R.-GRACE, S.: Oscillation of higher-order nonlinear difference equations of neutral type, Appl. Math. Lett. 12 (1999), no. 8, 77-83, doi:10.1016/S0893-9659(99)00126-3.

[3] AGARWAL, R.-THANDAPANI, E. -WONG, P.: Oscillation of higher-order neutral difference equation, Appl. Math. Lett. 10 (1997), no.1, 71-78, doi:10.1016/S08939659(96)00114-0.

[4] ANDRUCH-SOBIŁO, A.-MIGDA, M.: On the rational recursive sequence $x_{n+1}=$ $\frac{a x_{n-1}}{b+c x_{n} x_{n-1}}$, Tatra Mt. Math. Publ. 43 (2009) 1-9, doi:10.2478/v10127-009-0020-y.

[5] BOLAT, Y.-AKIN, Ö.: Oscillatory behaviour of a higher-order nonlinear neutral type functional difference equation with oscillating coefficients, Appl. Math. Lett. 17 (2004), no. 9, 1073-1078, doi:10.1016/S0893-9659(99)00126-3.

[6] DIBLÍK, J.-RŮŽIČKOVÁ, M.-SCHMEIDEL, E.: Asymptotically periodic solutions of Volterra difference equations Tatra Mt. Math. Publ. (43) (2009), 51-61, doi:10.2478/v10127-009-0024-7.

[7] DIBLÍK, J.-RŮŽIČKOVÁ, M.-SCHMEIDEL E.: Asymptotically periodic solutions of Volterra systems of difference equations, Comput. Math. Appl.59 (2010), no.8, 2854-2867, doi:10.1016/j.camwa.2010.01.055.

[8] DIBLÍK, J.-RŮŽIČKOVÁ, M.-SCHMEIDEL, E.-ZBASZYNIAK, M.: Weighted asymptotically periodic solutions of linear Volterra difference equations, Abstr. Appl. Anal. 2011 (ID 37098): 1-14, doi10.1155/2011/370982.

[9] ELAYDI, S.: Periodicity and stability of linear Volterra difference systems, J. Math. Anal. Appl. 181 (1994), no. 2, 483-492, doi:10.1006/jmaa.1994.1037.

[10] FURUMOCHI, T.: Periodic solutions of Volterra difference equations and attractivity, Nonlinear Anal. (47)(2001), no. 6, 4013-4024, doi:10.1016/S0362-546X(01)00520-X.

[11] JANKOWSKI, R.-SCHMEIDEL, E.: Stability by fixed point theory for functional differential equations, Int. J. Difference Equ. 9 (2014) no.i, 77-86.

[12] JANKOWSKI, R.-SCHMEIDEL, E.: Asymptotically zero solution of a class of higher nonlinear neutral difference equations with quasidifferences, Discrete Contin. Dyn. Syst. (B), 19 (2014), no. 8, 2691-2696, doi:10.3934/dcdsb.2014.19.2691.

[13] KOLMANOVSKI, V.-MYSHKIS, A.: Introduction to the Theory and Applications of Functional Differential Equations. Kluwer, Dordrecht, 1999.

[14] KOSMAlA, W.-KUlenoviĆ, M.-LADAS, G.-TEIXEIRAI, C.: On the recursive sequence $y_{n+1}=\frac{p+y_{n-1}}{q y_{n}+y_{n-1}}$, J. Math. Anal. Appl. 251 (2000), no. 2, 571-586, doi:10.1006/jmaa.2000.7032.

[15] MIGDA, M.-ZHANG, G.: Monotone solutions of neutral difference equations of odd order, J. Difference Equ. Appl. 10 (2007), no. 7, 691-703, doi:10.1080/10236190410001702490.

[16] MIGDA, M.-SCHMEIDEL, E. -ZDANOWICZ, M.: Asymptotically zero solution of a class of higher nonlinear neutral difference equations with quasidifferences, Appl. Anal. Discrete Math. 9 (2015), no. 2, 271-284, doi:10.2298/AADM150811016M. 


\section{EWA SCHMEIDEL-MAtGORZATA ZDANOWICZ}

[17] MIGDA, M.-SCHMEIDEL, E. -ZDANOWICZ, M.: Boundedness of $k$-dimensional system of nonlinear difference equations of neutral type, Electron. J. Qual. Theory Differ. Equ. 80 (2015), 1-17, doi:10.14232/ejqtde.2015.1.80.

[18] MYSCHKIS, A.D.: Lineare Differentialgleichungen mit Nacheilendem Argument. VEB Deutscher Verlag der Wissenschaften, Berlin, 1955.

[19] NALINI, S.-BANU, S. M.: New approach to periodicity of neutral type delay difference equations, Appl. Math. Sci. 48 (2015), no. 9, 2371-2379, doi:10.12988/ams.2015.53218.

[20] PARHI, N.-TRIPATHY, A.K.: Oscillation of a class of nonlinear neutral difference equations of higher order, J. Math. Anal. Appl. 284 (2003), no. 2, 756-774, 2003. doi:10.1016/S0022-247X(03)00298-1.

[21] PHILOS, C.G.-PURNARAS, I. K.: The behaviour of the solutions of periodic linear neutral delay difference equations, J. Comput. Appl. Math. 175 (2005), no. 2, 209-230, doi:10.1016/j.cam.2004.05.020.

[22] REN, J.-SIEGMUND, S.-HAN, W.: Positive Periodic Solutions for Neutral Difference Equations with Variable Delay. ResearchGate, 2014. https://www.researchgate.net/publication/259574530

[23] SHARMA, S.: Metric Space. Discovery Publishing Pvt. Ltd, New Delhi, India, 1th edition, 2011.

[24] THANDAPANI, E.-KARUNAKARAN, R.-AROCKIASAMY, I.: Bounded nonoscillatory solutions of neutral type difference systems, J. Qual. Theory Differ Equ. 25 (2009), 1-8, 2009. doi:10.14232/ejqtde.2009.4.25.

[25] WANG, W.-YANG, X.: Positive periodic solutions for neutral functional difference equations, Int. J. Difference Equ. 7 (2012), no. 1, 99-109.

[26] WANG, Z.-SUN, J.: Asymptotic behavior of solutions of nonlinear higher-order neutral type difference equations, J. Difference Equ. Appl. 12 (2006), no. 5, 419-432, doi:10.1080/10236190500539352.

[27] ZHOU, Y.-HUANG, Y. Q.: Existence for nonoscillatory solutions of higher-order nonlinear neutral difference equations. J. Math. Anal. Appl. 280 (2003), no. 1, 63-76, doi:10.1016/S0022-247X(03)00017-9.

[28] ZHOU, Y.-ZHANG, B. G.: Existence of nonoscillatory solutions of higher-order neutral delay difference equations with variable coefficients, Comput. Math. Appl. 45 (2003), no. 6, 991-1000, doi:10.1016/S0898-1221(03)00074-9.

Received December 12, 2020

Institute of Computer Science

University of Bialystok

K. Ciotkowskiego $1 M$

$P L-15-245$ Biatystok

POLAND

E-mail: eschmeidel@math.uwb.edu.pl mzdan@math.uwb.edu.pl 